\title{
A novel incremental slide board test for speed skaters: Reliability analysis and comparison with a cycling test
}

\section{Tatiane Piucco*, Saray Giovana dos Santos, Ricardo Dantas de Lucas, Jonathan Ache Dias}

\author{
Biomechanics Laboratory, Federal University of Santa Catarina, Florianópolis, Brazil
}

Received 29 September 2014; accepted 2 January 2015

Available online 11 February 2015

\section{KEYWORDS}

Athletic performance;

Skating;

Exercise test;

Physical exertion

\begin{abstract}
Introduction: Exercise prescription from indices obtained from cycling or running treadmill incremental tests does not seem suitable for speed skaters. However, the specificity of laboratory skating assessments remains to be established.

Purpose: This study intended to assess the test-retest reliability of an incremental test performed on a slide board (SB), and its validity compared with a cycling protocol in order to determine aerobic performance indices in speed skaters.

Methods: Ten competitive inline speed skaters performed two incremental tests on an SB and one cycling incremental test. The intensity of SB test was determined by cadence, starting at 30 push-offs/min and increasing by three push-offs/min each minute, until volitional exhaustion. Maximal and submaximal values related to the anaerobic threshold (AT) of oxygen uptake $\left(\mathrm{VO}_{2}\right)$, pulmonary ventilation (VE), respiratory exchange (RER), heart rate (HR), rating of perceived effort (RPE), cadence (CAD), and blood lactate concentration ([Lac]max) were measured.

Results: No significant differences were found in any of the variables between test-retest on SB. High relative $(I C C>0.9)$ and absolute reliability (typical error of measure as $C_{\text {TEM }}<3.5 \%$ ) were found for $\mathrm{VO}_{2} \max , \mathrm{HRmax}$, [Lac]max, CADmax, $\mathrm{VO}_{2 \mathrm{AT}}, \mathrm{CAD}_{\mathrm{AT}}$, and $\mathrm{RPE}_{\mathrm{AT}}$. In comparison to $\mathrm{SB}$ test, the [Lac]max was significantly higher during cycling, and the $\mathrm{RPE}_{\mathrm{AT}}$ was lower. $\mathrm{VO}_{2} \mathrm{max}$, HRmax, CADmax, $\mathrm{VO}_{2 \mathrm{AT}}$ and $\mathrm{CAD}_{\mathrm{AT}}$ were largely correlated between cycling and $\mathrm{SB}(r>0.8)$. Conclusions: The findings suggest that SB test is reliable and adequate to evaluate aerobic performance indices of speed skaters.

(c) 2014 Consell Català de l'Esport. Generalitat de Catalunya. Published by Elsevier España, S.L.U. All rights reserved.
\end{abstract}

\footnotetext{
* Corresponding author.

E-mail address: tatianepiucco@yahoo.com.br (T. Piucco).
} 


\section{PALABRAS CLAVE}

Desempeño atlético; Patinaje; Test de esfuerzo; Esfuerzo físico
Nuevo test incremental en una base de deslizamiento para patinadores velocistas: análisis de confiabilidad y comparación con un test de ciclismo

\section{Resumen}

Introducción: La prescripción de ejercicios obtenidos por medio índices de tests de ciclismo o sobre la cinta de correr, parecen no ser apropiados para patinadores. Sin embargo, la especificidad de medidas de laboratorios para patinadores debe ser establecida.

Objetivo: Evaluar la confiabilidad del test-retest de un test incremental realizado en una base de deslizamiento (BS), así como la validad del mismo comparado con un protocolo de ciclismo para determinar índices aeróbicos en el desempeño de patinadores velocistas.

Métodos: Diez patinadores velocistas inline ejecutaron dos tests incrementales sobre un BS y un test incremental de ciclismo. La intensidad del test sobre BS fue determinada mediante la cadencia, comenzando en 30 empujes/min y aumentando en tres empujes/min a cada minuto hasta el agotamiento volitivo. Fueron medidos valores máximos e submáximos relacionados con el umbral anaeróbico (UA) del consumo de oxígeno $\left(\mathrm{VO}_{2}\right)$, ventilación pulmonar (VP), intercambio respiratorio (IR), frecuencia cardíaca (FC), escala de percepción de esfuerzo (EPE), cadencia (CAD) y lactato sanguíneo ([Lac]max).

Resultados: No se encontraron diferencias significativas entre test-retest sobre la BS en ninguna de las variables. Se obtuvieron niveles elevados en el coeficiente intercalase (ICC $>0.9)$ y en la confiabilidad absoluta (error típico de medida $\mathrm{CV}_{\mathrm{TEM}}<3.5 \%$ ) para el $\mathrm{VO}_{2}$ max, $\mathrm{FCmax}$, [Lac]max, CADmax, $\mathrm{VO}_{2 \mathrm{AT}}, \mathrm{CAD}_{\mathrm{AT}}$, and $\mathrm{EPE}_{\mathrm{AT}}$. En comparación con el test de $\mathrm{BS}$, el [Lac]max fue significantemente más alto durante el test de ciclismo y la $\mathrm{EPE}_{\mathrm{AT}}$ fue más baja. $\mathrm{El} \mathrm{VO}_{2} \mathrm{max}, \mathrm{FCmax}$, CADmax, $\mathrm{VO}_{2 A T}$ and $\mathrm{CAD}_{A T}$ tuvieron correlación alta entre el test de ciclismo y el de $\mathrm{BS}(\mathrm{r}>0.8)$. Conclusión: Los resultados obtenidos sugieren que el test de BS es confiable y adecuado para evaluar índices de desempeño de patinadores velocistas.

(c) 2014 Consell Català de l'Esport. Generalitat de Catalunya. Publicado por Elsevier España, S.L.U. Todos los derechos reservados.

\section{Introduction}

Skating sports involve both aerobic and anaerobic energy supply. ${ }^{1,2}$ During the start, a large amount of anaerobic energy contribution is necessary to accelerate, and then, the last lap is predominantly covered on the basis of aerobic power. Even during the last lap of a $1500 \mathrm{~m}$ track race the energy is supplied by greater than $90 \%$ aerobic sources. ${ }^{1}$ This reveals the importance of aerobic fitness for professional inline or on ice speed skaters.

Aerobic fitness tests are largely used to monitoring endurance performance, and to control and prescribe training intensities during speed skating. ${ }^{3}$ To be effective, the performance evaluations for exercise prescription must be valid, reliable and movement-specific. It is generally accepted that optimal adaptations can be obtained from training loads specifically related to the sport activity itself, due to the physiological and neuromuscular specificity. 4,5

Exercise prescription from measurements obtained from cycling or running treadmill incremental tests does not seem suitable for speed skaters. ${ }^{6,7}$ However, the specificity of laboratory skating evaluations remains to be established, particularly because skating activities are difficult to simulate in the laboratory. ${ }^{3}$ Since the development of the skating treadmill in 1993, there has been little research on the skating treadmill's validity to elicit a $\mathrm{VO}_{2} \mathrm{max}$, or determining what type of protocol to use for evaluating physiological indices. ${ }^{8}$ Also, skating treadmills are very expensive and challenging to be used by coaches to optimise the training programmes of athletes through periodic laboratory evaluation.

Given the importance of aerobic parameter assessment to monitoring inline or on-ice speed skaters, it is valuable to develop an appropriate test for these athletes. In this sense, the SB has been widely used as an off-ice training modality by speed skaters, since it seems to mimic the speed skating gesture. However, to the best of our knowledge, there are no studies attempting to validate a specific test to evaluate aerobic indices of speed skaters or using a slide board (SB) as ergometer. The developing of an incremental test using the SB may allow for a simple and low cost sport-specific evaluation of speed skaters.

Thus, the purpose of this study was twofold: (1) to assess the test-retest reliability of a short incremental test performed on SB; (2) to compare maximal and submaximal aerobic indices obtained from cycling and SB skating incremental tests.

\section{Material and methods}

\section{Participants}

Eight male and two female competitive inline speed skaters voluntarily participated in the study. They all had SB training experience and have skating for at least three years. The mean age was $30.6 \pm 6$ years. The mean body mass, percentage of body fat and height were respectively, $71.4 \pm 11 \mathrm{~kg}$, 
$17.4 \pm 5.7 \%$, and $1.73 \pm 0.07 \mathrm{~m}$ for males, and $62.3 \pm 1.5 \mathrm{~kg}$, $25.9 \pm 2.05 \%$ and $1.66 \pm 2.2 \mathrm{~m}$ for females. The study was conducted in accordance with ethical principles for medical research involving human and in accordance with ethical standards of the Local University Human Research Ethics Committee. All participants signed an informed consent document with a detailed description of the aims, benefits and risks of participating in the study, as well as data protection.

\section{Procedures}

The participants were instructed to refrain from heavy training, maintain a regular diet $24 \mathrm{~h}$ prior to testing, and to abstain from the ingestion of any stimulant (caffeine drink, nicotine, etc.) or alcohol during the preceding testing day. All participants were familiarised with the tests and the equipment prior the data collection.

Three incremental tests were performed in laboratorycontrolled conditions: a maximal incremental cadence cycle ergometer test, and two maximal incremental cadence SB tests to verify the test-retest reliability. The tests were performed two to four days apart, at the same time of day and room temperature in order to ensure similar environmental conditions.

\section{Incremental cycling test}

The cycling protocol was performed on a Lode Excalibur Sport Cycle Ergometer (Groninger, Holland). Prior to the maximal test, a 5-min warm-up at a workload of 50-60 W with a cadence of $90 \mathrm{rpm}$ was performed. After a threeminute rest, the participants started the test at an initial workload relative to their body weight $\left(2.75 \mathrm{~W} \mathrm{~kg}^{-1}\right)$ with the cadence increased by $10 \mathrm{rpm}$ each minute from an initial cadence of $70 \mathrm{rpm} .{ }^{9}$ The test was terminated when the selected cadence could no longer be maintained or at volitional exhaustion.

\section{Incremental SB test}

The SB protocol was performed on an instrumented SB $(2.0 \mathrm{~cm} \times 0.6 \mathrm{~cm} \times 0.025 \mathrm{~cm})$ developed specifically for this project (Fig. 1). The SB surface was made of polyethylene (friction coefficient $=0.1$ ) and a non-slip material (ethylene vinyl acetate - EVA) was placed underneath. Two optical

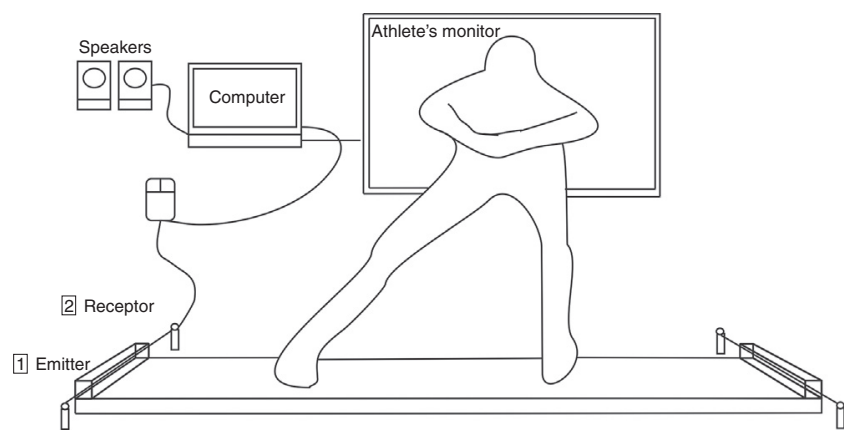

Figure 1 Instrumented SB scheme. 1 - photoemitter; 2 photordeceptor. sensors, connected to a computer, were placed at both extremities of the SB to detect the movement of the athletes' feet, and to determine the contact time at the lateral stoppers to indicate the athletes' cadence. Specific software was developed to control and help the athlete to keep the pace by providing visual and auditory feedback, and also to determine the end of the test by means of the signals input from the SB. The subject wore a pair of fleece socks to skate on SB during the test. The participants performed a five-minute warm-up at a cadence of 30 push-offs per minute. After a 3-min rest, the test began with a cadence of 30 push-off/min and it increased by three push-off/min every minute. The participants were asked to maintain a constant skating posture, and they were free to move their arms during the test. The test was completed when the selected cadence could no longer be maintained or at volitional exhaustion. Identical procedures were applied during the re-test.

Participants were verbally encouraged to exert maximum effort during the tests. The rate of perceived exertion (RPE) during the tests was accessed by the Borg scale (6-20 points) at the end of each stage. ${ }^{10}$ Ventilation (VE), respiratory exchange ratio (RER) and oxygen consumption $\left(\mathrm{VO}_{2}\right)$ were measured breath-by-breath using a gas analyser (Quark PFT Ergo, Cosmed, Rome, Italy), calibrated according to manufacturer's instructions prior to each test. $\mathrm{VO}_{2}$ max was considered to be the highest value averaged over 15-s. The attainment of $\mathrm{VO}_{2} \max$ was defined using the criteria proposed by Howley et al. ${ }^{11}$ The maximal cadence (CADmax) was defined as the maximal number of push-offs/min reached during the SB test. If the final stage was not completed, the CADmax was calculated according to the follow equation adapted from Kuipers et al. ${ }^{12}$ :

$C A D_{\max }=C A D_{f}+\left(\frac{t}{60 \times 3}\right)$

with $C A D_{f}$ the cadence of the final stage completed, $t$ the uncompleted stage time (s), 60 the stage duration (s) and 3 the cadence increment per stage. Blood samples were collected from subjects' earlobe one, three, and five minutes following test completion to assess the maximal blood lactate concentration ([Lac]max). [Lac] were assessed using an electrochemical analyser (YSI 2700 STAT, Yellow Springs, $\mathrm{OH}$, USA), calibrated according to the manufacturer's recommendations before each analysis. The ventilatory threshold (VT) intensity was determined by two experienced evaluators, established as an increase in respiratory equivalent for $\mathrm{O}_{2}$ and $\mathrm{CO}_{2}$ respectively. ${ }^{13} \mathrm{D}$-max method ${ }^{14}$ was used to identify the heart rate deflection point (HRDP), which is related to the anaerobic threshold (AT). ${ }^{15}$

$A$ paired $t$-test was used to compare data obtained from the two SB trials in a test-retest fashion and between the SB and cycling tests. Heteroscedasticity of all variables were examined by Bland-Altman plotting of the absolute individual differences vs. the individual means. The slope of the linear regression of this data was tested against zero, in order to assess the relationship significance. ${ }^{16}$ Intraclass correlation coefficients (ICC) and typical error of measurement (TEM) were calculated according to Hopkins ${ }^{17}$ to determine the test-retest reliability. The TEM was 
Table 1 Test-retest reliability scores of maximal and submaximal (HRDP) variables (mean \pm SD) during incremental SB test.

\begin{tabular}{|c|c|c|c|c|c|}
\hline & Test & Retest & $\mathrm{CV}_{\mathrm{TEM}}(\%)$ & ICC (95\%CI) & Bias \\
\hline $\mathrm{VO}_{2} \max \left(\mathrm{ml} \mathrm{kg}^{-1} \mathrm{~min}^{-1}\right)$ & $47.5 \pm 7.7$ & $47.6 \pm 6.3$ & 3.18 & $0.97(0.91-0.99)$ & 0.09 \\
\hline HRmax (bpm) & $190.9 \pm 8.9$ & $189.6 \pm 6.8$ & 1.19 & $0.95(0.800-0.99)$ & -1.30 \\
\hline RERmax & $1.21 \pm 0.12$ & $1.15 \pm 0.07$ & 7.25 & $-0.41(-1.86$ to 0.73$)$ & -0.06 \\
\hline $\operatorname{VEmax}\left(\operatorname{lmin}^{-1}\right)$ & $115.1 \pm 21.4$ & $111.4 \pm 19$ & 6.32 & $0.74(0.03-0.93)$ & -3.60 \\
\hline CADmax (Push-off min ${ }^{-1}$ ) & $64.0 \pm 9.3$ & $64.9 \pm 9.5$ & 1.21 & $0.99(0.98-0.99)$ & 0.60 \\
\hline$[\mathrm{Lac}] \max \left(\mathrm{mmol} \mathrm{l}^{-1}\right)$ & $10.3 \pm 1.9$ & $10.2 \pm 1.9$ & 6.72 & $0.92(0.70-0.98)$ & -0.27 \\
\hline RPEmax & $17.2 \pm 0.6$ & $17.1 \pm 0.5$ & 4.01 & $0.86(0.47-0.96)$ & -0.10 \\
\hline $\mathrm{VO}_{2 \mathrm{AT}}\left(\mathrm{ml} \mathrm{kg} \mathrm{kg}^{-1} \mathrm{~min}^{-1}\right)$ & $42.35 \pm 5.4$ & $41.82 \pm 5.7$ & 4.90 & $0.93(0.74-0.98)$ & 0.53 \\
\hline $\mathrm{CAD}_{\mathrm{AT}}$ (Push-off $\mathrm{min}^{-1}$ ) & $53.4 \pm 6.9$ & $53.7 \pm 8.5$ & 3.47 & $0.97(0.89-0.99)$ & -0.30 \\
\hline HRDP (bpm) & $175 \pm 11.2$ & $171 \pm 5.8$ & 3.26 & $0.72(0.06-0.93)$ & 3.83 \\
\hline$V_{A T}\left(\operatorname{lmin}^{-1}\right)$ & $77.9 \pm 8.9$ & $75.9 \pm 10.2$ & 8.90 & $0.68(-0.20$ to 0.92$)$ & 2.03 \\
\hline $\mathrm{RPE}_{\mathrm{AT}}$ & $15.6 \pm 1.4$ & $15.4 \pm 1.4$ & 2.84 & $0.95(0.80-0.98)$ & 0.20 \\
\hline
\end{tabular}

$\mathrm{CV}_{\mathrm{TEM}}(\%)=$ typical error of measure expressed as coefficient of variation; ICC $=$ intraclass correlation coefficient; $\mathrm{VO}_{2} \mathrm{max}=\mathrm{maximal}$ oxygen uptake; HRmax = maximal heart rate; VEmax = maximal ventilation; CADmax = maximal cadence; RERmax = maximal respiratory exchange ratio; [Lac] max = maximal lactate concentration; RPEmax = maximal rate of perceived exertion; $\mathrm{VO}_{2 \mathrm{AT}}=\mathrm{oxygen}_{\mathrm{Bptake}}$ at $\mathrm{AT}$; $C A D_{A T}=$ cadence at $A T ; H R D P=$ heart rate deflection point; $V E_{A T}=$ ventilation at $A T ; R P E_{A T}=$ rate of perceived exertion at $A T$.

expressed as coefficient of variation $\left(\mathrm{CV}_{\mathrm{TEM}}\right)$. The ICCS were interpreted as follows: $0.90-0.99$ as high reliability; $0.80-0.89$ as good reliability; $0.70-0.79$ as fair reliability; and $<0.69$ as poor reliability. ${ }^{18}$ Pearson's correlations were used to examine the relationships between cycle ergometer and SB tests. The following criterion was adopted for interpreting the magnitude of correlation between variables: $<0.1$ as trivial; $0.11-0.3$ as small; $0.31-0.5$ as moderate; 0.51-0.7 as large; $0.71-0.9$ as very large; and $0.91-1.0$ as almost perfect. ${ }^{19}$ Statistical analysis was conducted using Statistical Package for Social Sciences (SPSS Inc. v.17.0, Chicago, USA) and the confidence level was set at $5 \%$.
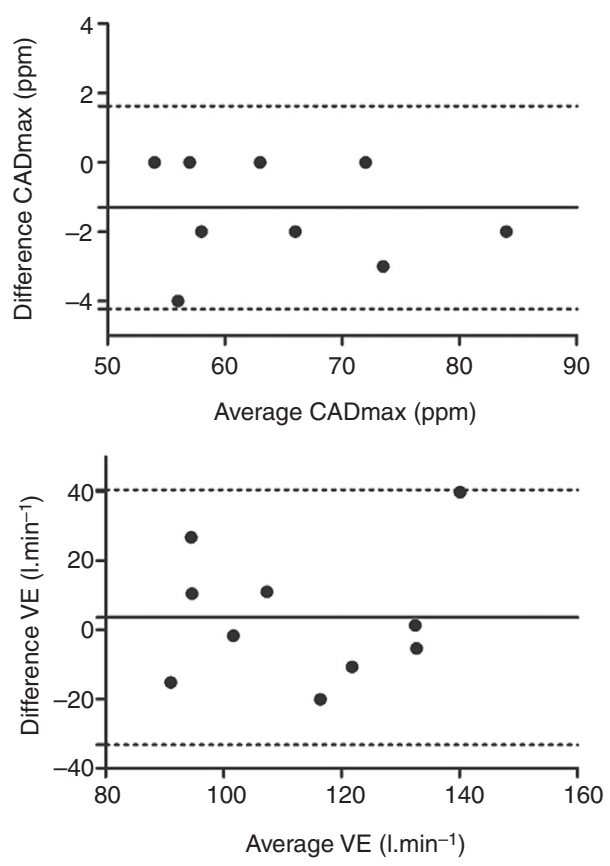

\section{Results}

During the SB protocol, all participants reached at least three of five criteria for $\mathrm{VO}_{2} \mathrm{max}$ attainment, according to Howley et al., ${ }^{11} 7 / 10$ subjects attained a $\mathrm{VO}_{2} \max$ plateau, 7/10 attained predicted HRmax, 9/10 achieved an $\mathrm{RER} \geq 1.1,9 / 10$ achieved $[\mathrm{LaC}] \geq 8 \mathrm{mmol} \mathrm{l}^{-1}$, and $3 / 10$ attained an RPE of 18 .

Table 1 shows test-retest reliability scores of the maximal and submaximal variables. No significant differences were found between VT and HRDP method for all variables analysed during test and retest. In this sense, the submaximal values related to the HRDP were used for the following
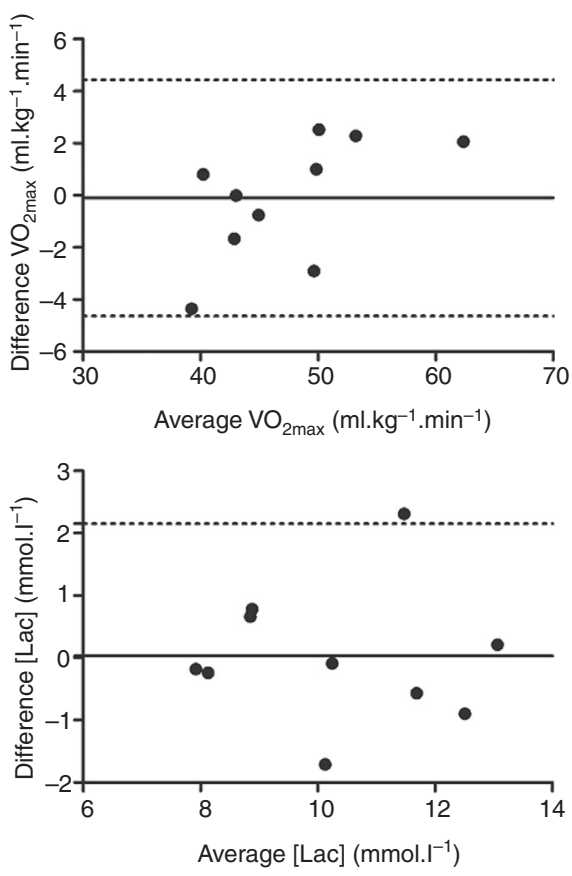

Figure 2 Bland-Altman plots showing the agreement between test and retest in SB sessions for $\mathrm{VO}_{2} \mathrm{max}, \mathrm{CADmax} \mathrm{VEmax}$ and [Lac]max. Solid line = bias; dashed lines $=95 \%$ limits of agreement. 
analysis to be considered as a more practical application. No significant differences were found between test and retest values for all variables analysed. All data analysed presented homoscedasticity. The results show low within-individual variation, very low bias and high reliability for $\mathrm{VO}_{2}, \mathrm{HR}$ and $C A D$ maximal values. Maximal and submaximal values of $\mathrm{VE}$ and RER showed poor reliability.

Fig. 2 illustrates the Bland-Altman plots for the reliability analysis for some of the maximal variables.

No significant differences for maximal $\mathrm{VO}_{2}, \mathrm{VE}, \mathrm{RER}$ and RPE values (Table 2) were found between cycling and SB tests. Regarding the submaximal values obtained during SB, only $\mathrm{RPE}_{\mathrm{AT}}$ were significantly different $(p<0.01)$ compared to cycling test. Large correlations were found between cycling and $\mathrm{SB}$ for $\mathrm{VO}_{2} \max , \mathrm{HRmax}, \mathrm{CADmax}, \mathrm{VO}_{A T}$ and $\mathrm{CAD}_{\mathrm{AT}}$.

The relationship between the performance on SB $\left(\mathrm{VO}_{2} \mathrm{max}\right)$ and the maximal cadence reached during SB (CADmax) are shown in Fig. 3.

\section{Discussion}

The first aim of this study was to evaluate the reliability of physiological measures during SB testing, which mimics the skating gesture. No differences were found for all maximal variables between test and retest trials. In general, the reliability scores obtained from the SB test showed that it is a practical and consistent incremental test. The $\mathrm{VO}_{2}$ max, HRmax, CADmax, CAD and RPE submaximal measures showed the highest test-retest reliability scores (ICC $>0.9 ; \mathrm{CV}_{\mathrm{TEM}}<3.5 \%$, Table 1). Considering most maximal variables, within-individual variations (TEM) between test and retest were smaller than those found for similar protocols in cycle ergometer ${ }^{9,20}$ and field hockey skating test. ${ }^{21}$ Also the Within-participants variation is the most important analysis when considering the reliability of measurements, because it affects the estimates precision of change in the

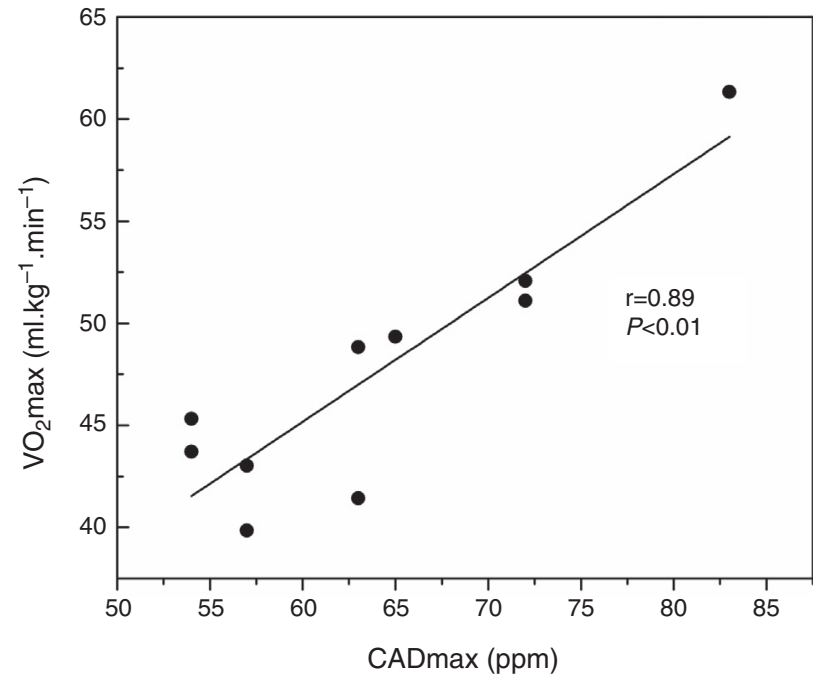

Figure 3 Relationship between $\mathrm{VO}_{2} \max$ and CADmax obtained on SB incremental test.

variable of an experimental study. ${ }^{17}$ From a practical point of view, Hopkins ${ }^{17}$ pointed out that about 1.5-2.0 times the typical error could be used as a threshold above which any individual change would be interpreted as "real" following an intervention. For instance, considering the $\mathrm{CV}_{\mathrm{TEM}}$ value found for the CADmax (e.g. 1.2\%), this threshold would be around $2.4 \%$.

Comparisons between the SB test and cycling test indicate higher [Lac]max values and lower $\mathrm{RPE}_{\mathrm{AT}}$ during SB protocol compared with cycling (Table 2). Most participants reached a slightly lower maximal and submaximal $\mathrm{VO}_{2}$ and VE values and higher HR during SB protocol. Furthermore, significant correlations for $\mathrm{VO}_{2} \max$, HRmax, CADmax, $\mathrm{VO}_{2 \mathrm{AT}}$ and $\mathrm{CAD}_{\mathrm{AT}}$ values exist between $\mathrm{SB}$ and cycle ergometer protocols. There is data in the literature comparing the physiological parameters amongst skating, cycling and

Table 2 Comparison and correlation values of maximal and submaximal variables (mean \pm SD) between SB and cycling protocols.

\begin{tabular}{|c|c|c|c|}
\hline & SB & Cycling & $r$ \\
\hline $\mathrm{VO}_{2} \max \left(\mathrm{ml} \mathrm{kg}^{-1} \mathrm{~min}^{-1}\right)$ & $47.5 \pm 7.7$ & $48.4 \pm 8.8$ & $0.91^{b}$ \\
\hline HRmax (bpm) & $190.9 \pm 8.9$ & $190 \pm 10$ & $0.87^{b}$ \\
\hline RERmax & $1.21 \pm 0.12$ & $1.29 \pm 0.1$ & 0.22 \\
\hline $\operatorname{VEmax}\left(\operatorname{lmin}^{-1}\right)$ & $115.07 \pm 21.4$ & $127.4 \pm 18$ & 0.40 \\
\hline CADmax (Push-off min $^{-1}$ ) & $64.0 \pm 9.3$ & $127.0 \pm 20.5$ & $0.83^{b}$ \\
\hline$[\mathrm{Lac}] \max \left(\mathrm{mmol} \mathrm{l}^{-1}\right)$ & $10.3 \pm 1.9$ & $13.4 \pm 2.3^{a}$ & 0.60 \\
\hline $\mathrm{RPE}_{\max }$ & $17.2 \pm 0.6$ & $17.3 \pm 0.48$ & 0.52 \\
\hline $\mathrm{VO}_{2 \mathrm{AT}}\left(\mathrm{ml} \mathrm{kg}^{-1} \mathrm{~min}^{-1}\right)$ & $42.35 \pm 5.4$ & $44.1 \pm 6.4$ & $0.90^{\mathrm{b}}$ \\
\hline CAD $_{\text {AT }}$ (Push-off min $\left.^{-1}\right)^{c}$ & $53.4 \pm 6.9$ & $103 \pm 14.9$ & $0.80^{\mathrm{b}}$ \\
\hline HRDP (bpm) & $175 \pm 11.2$ & $172.6 \pm 12.2$ & 0.32 \\
\hline $\mathrm{VE}_{\mathrm{AT}}\left(\mathrm{lmin}^{-1}\right)$ & $77.9 \pm 8.9$ & $88.3 \pm 21.1$ & 0.50 \\
\hline $\mathrm{RPE}_{A T}$ & $15.6 \pm 1.4$ & $14.6 \pm 1.5^{a}$ & 0.54 \\
\hline $\mathrm{CAD}_{\mathrm{AT}}(\% \max )$ & $88.4 \pm 4.6$ & $81.7 \pm 8.2$ & 0.50 \\
\hline
\end{tabular}

a Significant difference $(p<0.05)$.

b Significant correlation $(p<0.05)$.

c Cadence values not compared due to different units. $\mathrm{VO}_{2} \max =$ maximal oxygen uptake; HRmax = maximal heart rate; VEmax = maximal ventilation; $\mathrm{CADmax}$ = maximal cadence; RERmax = maximal respiratory exchange ratio; [Lac]max = maximal lactate concentration; RPE$\max =$ maximal rate of perceived exertion; $\mathrm{VO}_{2 A T}=$ oxygen uptake at $\mathrm{AT}$; $\mathrm{CAD}_{\mathrm{AT}}=$ cadence at $\mathrm{AT}$; $\mathrm{HRDP}=$ heart rate deflection point; $\mathrm{VE}_{\mathrm{AT}}=$ ventilation at $A T ; \mathrm{RPE}_{\mathrm{AT}}=$ rate of perceived exertion at $\mathrm{AT}$. 
running activities. ${ }^{6,7,22-25}$ Despite some differences, cycling parameters seem to be more similar to skating activity than running. ${ }^{23,24}$ Furthermore, the testing protocol design can also affect physiological responses during exercise. ${ }^{26}$ Cadence vs. workload incremental cycling tests show differences in peak workloads. However, both protocols produce similar peak $\mathrm{VO}_{2}$ values, which reflect on a lower cycling economy during cadence-increase protocols. ${ }^{9}$

The findings of the present study are consistent with the previous investigations of Foster et al. ${ }^{25}$ and Snyder et al. ${ }^{23}$ that have demonstrated lower $\mathrm{VO}_{2}, \mathrm{VE}$ and $\mathrm{RER}$ values and higher HR and [Lac] values during treadmill skating protocol when comparing with cycling exercise. Krieg et al. ${ }^{6}$ also found lower $\mathrm{VO}_{2}$ max and higher $\mathrm{HR}$ and [Lac] values during skating when compared to cycle testing, but higher submaximal $\mathrm{VO}_{2}$ and RER associated with a fixed [Lac] of $4 \mathrm{mmol} \mathrm{l}^{-1}$. Perhaps the field skating test conditions in Krieg et al.'s ${ }^{6}$ study could explain those differences, because the asphalt friction coefficient and skating variables such as uncontrolled posture, stride frequency, glide and push-off duration, crossover stride, can alter physiological responses between treadmill and field skating. ${ }^{27}$ Also, Krieg et al. ${ }^{6}$ utilised a discontinuous protocol and the [Lac] could be decreased due to the exercise interruptions, and as well the lactate vs. $\mathrm{VO}_{2}$ relationship.

Other possible explanations for the lower $\mathrm{VO}_{2}$ max attained during skating exercise can be related to both a smaller active muscle mass and to a restriction of muscle blood flow during skating when compared to cycling. ${ }^{7,25}$ These conditions depend on skating posture, surface characteristics and skater motor skill. ${ }^{6,28}$ A lower skater body position induces a greater reduction in $\mathrm{VO}_{2} \mathrm{max}$, consistent with a reduction in muscle blood flow secondary to high intramuscular forces during skating exercise. ${ }^{25}$

High intramuscular forces could also explain the high HR during skating, since it might lead to a disproportionate increase in $\mathrm{HR}$ relative to $\mathrm{VO}_{2}$. Such situation is frequently observed during resistance training or attributable to the activated muscle ischaemia and an increase in systemic arterial pressure. ${ }^{29}$ This is consistent with the concept that the high forces within the muscle act to compress the smaller arterioles thereby increasing the HR during skating.

For submaximal comparisons between cycling and SB modalities, we chose to use the HRDP as an aerobic index to access the AT. The HRDP has potential to be used for training regulation purposes due to its feasibility. The results indicate similar values for $\mathrm{VO}_{2}, \mathrm{HR}$ and VE at AT. Further, the cadence at AT found for each ergometer was significantly correlated (Table 2). This result suggests that HRDP occurred at the same relative intensity when compared cycling and SB exercises, and this index could be a viable method to prescribe submaximal intensity during SB training. The high relationship score $(r=0.89)$ found between CADmax and $\mathrm{VO}_{2}$ max relationship (Fig. 3) also suggest that the maximal cadence or stage reached during the test can be an indirect index to indicate training level.

Since board skating evokes much more specific physiological and biomechanical responses, ${ }^{30}$ it can be used not only for testing, but for training purposes as well. Highly fit individuals may require a higher training stimulus to achieve a significant training effect, and SB skating could be used to perform interval-training sessions. Intensity is easily manipulated by changes in cadence or by increasing the friction coefficient on the board surface. However, interventionbased studies are necessary in order to better understand the likely benefits applied to SB training compared to actual skating movement.

The good agreement between test-retest data suggests that the SB incremental test is reliable. Furthermore, the large correlations and the lack of differences in the physiological variables between the SB skating and cycling protocols suggest that the SB test is valid and adequate to evaluate aerobic indices of performance in speed skaters. Therefore, the use of indirect indices, i.e. HRDP and CADmax, to identify the exercise intensities and training level has a more practical application for coaches and may provide a more feasible alternative to laboratory-based tests when a large number of athletes need to be monitored for changes in performance and fitness over a competitive season. Future studies are necessary to better understand the biomechanics and physiology of slide board skating movement and its similarity with skating movement.

\section{Conflict of interest}

Authors declare that they do not have any conflict of interests.

\section{Acknowledgments}

The authors wish to acknowledge and thank the volunteer athletes of Santa Catarina's Federation of Hockey and Skating (FCHP) for their cooperation. This work was supported by the CAPES Brazil Agency.

\section{References}

1. DeKoning JJ, van Ingen Schenau GJ. Performance-determining factors in speed skating. In: Zatsiorski VM, editor. Biomechanics in sport: performance improvement and injury prevention. Malden: Blackwell Science; 2000. p. 232-46.

2. Foster C, de Koning JJ, Hettinga F, Lampen J, Dodge C, Bobbert $M$, et al. Effect of competitive distance on energy expenditure during simulated competition International. J Sports Med. 2004;25:198-204.

3. Foster C, Thompson NN, Synder AC. Ergometric studies with speed skaters: evolution of laboratory methods. J Strength Cond Res. 1993;7:193-200.

4. de Boer RW, Ettema GJC, Faessen B, Krekels H, Hollander AP, de Groot G, et al. Specific characteristics of speed skating: implications for the summer training. Med Sci Sports Exerc. 1987;19:504-10.

5. De Groot G, Hollander P, Sargeant J, van Ingen Schenau GJ, de Boer RW. Applied physiology of speed skating. J Sports Sci. 1987;5:249-59.

6. Krieg A, Meyer T, Clas S, Kindermann W. Characteristics of inline speedskating-Incremental tests and effect of drafting. Int J Sports Med. 2006;27:818-23.

7. Rundell KW. Compromised oxygen uptake in speed skaters during treadmill inline skating. Med Sci Sports Exerc. 1996;28:120-7.

8. Koepp KK, Janota JM. Comparison of $\mathrm{VO}_{2} \max$ and metabolic variables between treadmill running and treadmill skating. J Strength Cond Res. 2008;22:1-6. 
9. Deakin GB, Davie AJ, Zhou S. Reliability and validity of an incremental cadence cycle $\mathrm{VO}_{2}$ max testing protocol for trained cyclists. J Exerc Sci Fit. 2011;9:31-9.

10. Borg G. Psychophysical bases of perceived exertion. Med Sci Sports Exerc. 1982;14:377-81.

11. Howley ET, Bassett DR Jr, Welch HG. Criteria for maximal oxygen uptake: review and commentary. Med Sci Sports Exerc. 1995;27:1292-301.

12. Kuipers H, Verstappen FTJ, Geurten P, van Kranenburg G. Variability of aerobic performance in laboratory and its physiologic correlates. Int J Sports Med. 1985;6:197-201.

13. Reinhard U, Muller PH, Schmulling RM. Determination of anaerobic threshold by the ventilation equivalent in normal individuals. Respiration. 1979;38:36-42.

14. Kara M, Gokbel H, Bediz C. Determination of the heart rate deflection point by the Dmax method. J Sports Med Phys Fitness. 1996;36:31-4.

15. Bodner ME, Rhodes EC. A review of the concept of the heart rate deflection point. Sports Med. 2000;30:31-46.

16. Ludbrook J. Confidence in Altman-Bland plots: a critical review of the method of differences. Clin Exp Pharmacol Physiol. 2010;37:143-9.

17. Hopkins WG. Measures of reliability in sports medicine and science. Sports Med. 2000;30:1-15.

18. Currier DP. Elements of research in physical therapy. 2nd ed. Baltimore: Williams and Wilkins; 1990.

19. Hopkins WG, Marshall SW, Batterham M, Hanin J. Progressive statistics for studies in sports medicine and exercise science. Med Sci Sports Exerc. 2009;41:3-12.

20. Zhou S, Weston SB. Reliability of using the D-max method to define physiological responses to incremental exercise testing. Physiol Meas. 1997;18:145-54.
21. Petrella NJ, Montelpare WJ, Nystrom M, Plyley M, Faught BE. Validation of the FAST skating protocol to predict aerobic power in ice hockey players. Appl Physiol Nutr Metab. 2007;32:693-700.

22. Martinez ML, Modrego A, Ibanez Santos J, Grijalba A, Santesteban MD, Gorostiaga EM. Physiological comparison of roller skating, treadmill running and ergometer cycling. Int J Sports Med. 1993;14:72-7.

23. Snyder AC, O'Hagan KP, Clifford PS, Hoffman MD, Foster C. Exercise responses to inline skating: comparisons to running and cycling. Int J Sports Med. 1993;14:38-42.

24. Wallick ME, Porcari JP, Wallick SB, Berg KM, Brice GA, Arimond GR. Physiological responses to inline skating compared to treadmill running. Med Sci Sports Exerc. 1995;27:242-8.

25. Foster C, Rundell KW, Snyder AC, Stray-Gundersen J, Kemkers G, Thometz N, et al. Evidence for restricted muscle blood flow during speed skating. Med Sci Sports Exerc. 1999;31: 1433-40.

26. Bentley DJ, Newell J, Bishop D. Incremental exercise test design and analysis. Sports Med. 2007;37:575-86.

27. Nobes KJ, Montgomery DL, Pearsall DJ, Turcotte RA, Lefebvre $\mathrm{R}$, Whittom FA. Comparison of skating economy on-ice and on the skating treadmill. Can J Appl Physiol. 2003;28:1-11.

28. Carroll TR, Bacharach D, Kelly J, Rudrud E, Karns P. Metabolic cost of ice and inline skating in Division I collegiate ice hockey players. Can J Appl Physiol. 1993;18:255-62.

29. O'Leary DS. Autonomic mechanisms of muscle metaboreflex control of heart rate. J Appl Physiol. 1993;74:1748-54.

30. Kandou TWA, Houtman ILD, Bol EVD, de Boer RW, de Groot G, van Ingen Schenau GJ. Comparison of physiology and biomechanics of speed skating with cycling and with skateboard exercise. Can J Appl Physiol. 1987;12:31-6. 